\title{
PECULIARITIES OF HIGHER PSYCHOLOGICAL FUNCTIONS AND EMOTIONAL SPHERE IN PATIENTS WITH DEMENTIA OF VARIOUS TYPES ASSOCIATED WITH SUICIDAL RISK
}

\author{
Mudrenko I. \\ Sumy State University, Medical Institute, Ukraine
}

\begin{abstract}
The study involved 208 patients with dementia who were divided into three groups according to the type of dementia: 75 patients with Alzheimer's disease, 73 patients with vascular dementia and 60 patients with the mixed type of dementia. In each group, patients were divided into the main group (in which high suicidal risk (SR) was determined) and the control group (without signs of suicidal risk).

The aim of the study was to assess the influence of disturbances of higher psychological functions and emotional-volitional sphere on the formation of suicidal behavior (SB) in patients with different clinical types of dementia.

On the basis of clinical, pathopsychological, neuroimaging examination of patients we determined clinical and psychopathological peculiarities associated with high risk of suicide. The state of the following spheres of the psyche was determined: thinking, memory, will, emotions, attention, speech, perception, motor sphere.

Thus, it was established that torpidity of thinking, pseudomania and micromania, prevalence of hypomymia and hypothyroidism, inhibition of speech, attention fatigue and emotional disorders in the form of depressive affective manifestations are typical for patients with high risk of suicide. The patients of the control group without the signs of suicidal behavior have difficulties in planning and organization of activity, differed in psychomotor agitation, severity of fixative amnesia, and difficulty concentration.

The obtained data should be considered for diagnosis and prevention of suicidal behavior in this patient population.

Key words: thought disorder, memory impairment, attention disorder, perceptual disturbance, speech disturbance, emotions, vascular dementia, mixed dementia, dementia in Alzheimer's disease.
\end{abstract}

Introduction. According to statistics, from 5 to $25 \%$ of elderly people suffer from dementia. In absolute terms, it is at least 30 million patients in the world [1].

The semiotics of mental disorders in dementia includes a wide range of psychopathological disorders, namely cognitive, emotional and behavioral symptoms. Usually cognitive symptoms (higher mental, higher cortical, higher brain

Corresponding Author:

Mudrenko I.H., MD, PhD,

Sumy State University, Medical Institute, Department of Neurosurgery and Neurology, Lviv, Ukraine.E-mail: mudrenko.irina@gmail.com functions) include memory, intelligence, thinking, praxis, gnosis (perception), attention, speech. The impression of these mental functions causes violation of the processes of perception of the environment and social interaction of patients with dementia [2, 3, 4].

Non-congenital mental disorders in patients with dementia most commonly include depression, anxiety, agitation, aggression, insomnia and vagrancy [1-5].

About $40 \%$ of patients are known to have suicidal thoughts at the initial stages of dementia. Some authors prove the involvement of cognitive impairments to suicidal behavior. So the level of memory in elderly patients who committed suicide 
was lower than in patients with depression without suicidal manifestations [6]. In accordance with the concept of stress-diathesis, the basis of suicide is the cognitive (mental) control impairment, deficit of social functioning and impulsiveness [7, 8].

So far, modern literature has not adequately covered the mechanisms of the influence of higher mental functions and emotional sphere disorders on the formation of suicidal behavior in patients with vascular and degenerative dementia.

\section{Purposes, subjects and methods:}

2.1. Purpose was to study the influence of higher mental functions and emotional-volitional sphere disorders on the formation of suicidal behavior (SB) in patients with various clinical types of dementia.

2.2. Subjects \& Methods. The study involved 208 patients who underwent clinicalpsychopathological and neuroimaging examination in Sumy Regional Clinical Psychoneurological Dispensary, Sumy Regional Clinical Hospital for Veterans of War, Geriatric Boarding House, Sumy City Hospital No.4. The patients were divided into three groups according to the type of dementia: 75 patients with Alzheimer's disease, 73 patients with vascular dementia and 60 patients with mixed type of dementia. In each group, the patients were divided into the main group (which determined high suicide risk (SR)) and the control group (without the signs of suicidal risk). Thus, in the group of patients with Alzheimer's disease the main group composed 36 patients, the comparison group - 39 patients; in vascular dementia, 39 people were included in the main group and 34 in the comparison group; in mixed dementia, 30 patients composed the main group and 30 patients - the comparison group.

The diagnosis was established in accordance with the ICD-10.

Specification of clinico-psychopathological structure of higher mental functions was carried out following to the assessment of thought disorders, mnestic processes violations, emotional-volitional sphere and speech disorders, processes of attention and perception disturbance in different types of dementia taking into account the features of suicidal risk (SR) in these pathologies.
All thought disorders in accordance with the clinical classification (Sidorov P.I., Parniakov A.V., 2000) were divided into two groups: quantitative (pathology of the associative process) and qualitative (pathology of judgments and inferences).

Associative process pathology included violations of tempo, mobility and purposefulness of thinking, and pathology of judgments and inferences - intrusive thoughts, valuable and delusional ideas, as well as the ability to plan and organize activities.

Statistical processing of the results was performed with the Student's criterion and Fisher's exact test.

Conflict of interests. There is no conflict of interests.

3. Results and discussion. Statistical comparative analysis of thought disorders among patients with high SR in different types of dementia showed that the violation of the tempo of thinking in the form of its acceleration was more pronounced among patients with mixed dementia compared with patients with Alzheimer's disease ( $\mathrm{p} \leq 0.025, \mathrm{DK}=8.57, \mathrm{MI}=0.74)$. The study also showed that by mental mobility in patients with vascular dementia prevailed the detailed thinking compared to Alzheimer's disease ( $\mathrm{p} \leq$ $0.01, \mathrm{DK}=-3.75, \mathrm{MI}=0.50$ ) and mixed dementia ( $\mathrm{p} \leq 0.001, \mathrm{DK}=6.64, \mathrm{MI}=1.20)$, in which stiff thinking prevailed $((\mathrm{p} \leq 0.01, \mathrm{DK}=4.03, \mathrm{MI}=$ $0.47)$ and $(\mathrm{p} \leq 0.05, \mathrm{DK}=-3.36$, $\mathrm{MI}=0.30)$ respectively). Violation of the purposefulness of thinking in the form of disintegration of thought was more pronounced in patients with mixed type of dementia compared to vascular dementia $(\mathrm{p} \leq 0.05, \mathrm{DK}=-4.15, \mathrm{MI}=0.34)$.

Comparative analysis of speech impairment in patients with high SR in different types of dementia allowed to establish that the number of patients with stereotyped oral speech was greater in Alzheimer's disease than in vascular dementias ( $\mathrm{p} \leq 0.025$, DK $=4.15, \mathrm{MI}=0,43)$. It was also established that the number of patients with sensory aphasia prevailed in Alzheimer's disease $(\mathrm{p} \leq 0.025, \mathrm{DK}=4.15, \mathrm{MI}=0.43)$ and in mixed dementia $(p \leq 0.005$, $\mathrm{DC}=-5.29$, $\mathrm{MI}=0,81)$ in comparison with vascular dementia, and patients 
with optic-amnestic aphasia prevailed in mixed dementias than in vascular dementia ( $\mathrm{p} \leq 0.01$, $\mathrm{DK}=-2.65, \mathrm{MI}=0.34$ ).

Comparative analysis of volitional disorders among patients with high SR in different types of dementia was also conducted. It was found that the severity of the hypobulia distinguished patients with Alzheimer's disease compared to patients with vascular and mixed dementia $((\mathrm{p} \leq 0.005$, $\mathrm{DK}=-2.27, \mathrm{MI}=0.36)$ and $(\mathrm{p} \leq 0.00025$, $\mathrm{DK}=3,68$, $\mathrm{MI}=0.82)$ respectively), among which there were more patients with hypobulia $((\mathrm{p} \leq 0.025$, $\mathrm{DK}=4.42, \mathrm{MI}=0.43)$ and $(\mathrm{p} \leq 0.05, \mathrm{DK}=-4,31$, $\mathrm{MI}=0.41)$ respectively $)$ and echopraxia $((\mathrm{p} \leq 0.01$, $\mathrm{DK}=6.02, \mathrm{MI}==0.75)$ and $(\mathrm{p} \leq 0.025$, $\mathrm{DK}=$ $-5.56, \mathrm{MI}=0.60$ ) respectively). The number of patients with parabulia and parakinesia was higher in mixed dementia than in Alzheimer's disease $((\mathrm{p} \leq 0.01, \mathrm{DK}=-5.19, \mathrm{MI}=0.66)$ and $(\mathrm{p} \leq 0.0001$, $\mathrm{DC}=-11,58, \mathrm{MI}=2.16$ ) respectively). In vascular dementia, the number of patients with parakinesia was lower compared to patients with mixed dementia ( $\mathrm{p}<0.01$, DK $=-4.15$, $\mathrm{MI}=0.51)$, but the number of patients with psychomotor agitation was greater than with Alzheimer's disease $(\mathrm{p} \leq 0.005$, $\mathrm{DK}=7.43$, $\mathrm{MI}=0.94$ ).

The expressed hypomimia was typical for patients with Alzheimer's disease and mixed dementia as opposed to patients with vascular dementia $((\mathrm{p} \leq 0.001, \mathrm{DK}=4.68, \mathrm{MI}=0.82)$ and $(\mathrm{p} \leq 0.025, \mathrm{DC}=-3.48, \mathrm{MI}=0,38)$ respectively). The inhibition of libido was more pronounced in patients with Alzheimer's disease compared to patients with vascular and mixed types of dementia $((\mathrm{p} \leq 0.0001, \mathrm{DK}=10.20, \mathrm{MI}=3.72)$ and ( $\mathrm{p} \leq 0.0001, \mathrm{DK}=4,80, \mathrm{MI}=1.29)$ respectively. It should be noted that in the mixed type of dementia, the number of patients with inhibited sexual desire was greater than in vascular dementia ( $\leq 0.025, \mathrm{DK}=-5.40, \mathrm{MI}=0.51$ ).

Statistical comparative analysis of violations of the emotional sphere in the main group in different types of dementia was performed to understand the influence of SR in different types of dementia on the emotional sphere. It showed that the feeling of exhaustion was higher in patients with mixed type of dementia than in Alzheimer's disease $(\mathrm{p} \leq 0.005$, DC $=-3.01$, $\mathrm{MI}=0.50)$ and vascular dementia $(\mathrm{p} \leq 0.05$, DK $=$
-1.60, MI = 0.16). Emotional lability was the most pronounced in vascular dementia $(\mathrm{p} \leq 0.005$, DK $=$ $-3.84, \mathrm{MI}=0.61$ ), and the lability of the emotional sphere was more inherent to patients with mixed type of dementia than to patients with Alzheimer's disease $(p \leq 0,05, \mathrm{DK}=-2,90, \mathrm{MI}==0,31)$. Patients with Alzheimer's disease differed from patients with vascular dementia with a higher severity of depression ( $\mathrm{p} \leq 0.01, \mathrm{DK}=1.81$, MI $=0.24)$, anxiety $(\mathrm{p} \leq 0.05, \mathrm{DK}=2.22, \mathrm{MI}=0.25)$ and melancholia $(\mathrm{p} \leq 0.01, \mathrm{DK}=2.72, \mathrm{MI}=0.33)$.

The comparison of patients with high SR in different types of dementia made it possible to establish that fixative and progressive amnesia was more pronounced in patients with Alzheimer's disease $((\mathrm{p} \leq 0.01, \mathrm{DK}=-2.78, \mathrm{MI}==0.38)$ and $(\mathrm{p}$ $\leq 0.005, \mathrm{DK}=-2,27, \mathrm{MI}=0,36)$ respectively) and mixed dementia $((\mathrm{p} \leq 0,005, \mathrm{DK}=3,14, \mathrm{MI}=0,51)$ and ( $\mathrm{p} \leq 0,01, \mathrm{DK}=2,20, \mathrm{MI}=0,34)$, respectively) in comparison with vascular dementia. The tendency to describe the events that have never occurred in the life of patients (confabulations) was more typical for patients with vascular dementia compared to patients with Alzheimer's disease ( $\mathrm{p} \leq 0.025$, $\mathrm{DK}=$ 4.22, $\mathrm{MI}=0.48$ ).

Clinico-psychopathological analysis of perceptual disturbances allowed to establish some typical peculiarities, characteristic for patients with SR in different types of dementia.

Thus, it was established that the symptoms of depersonalization were more pronounced in mixed type of dementia compared with vascular dementia ( $\leq 0.05$, DK $=-3.36$, MI $=0.30)$ and Alzheimer's disease $(\mathrm{p} \leq 0.025, \mathrm{DK}=4.77, \mathrm{MI}=$ $=0.53$ ), and the symptoms of derealization were more pronounced in Alzheimer's disease and mixed dementia than in vascular dementia $((\mathrm{p} \leq 0.05$, $\mathrm{DK}=-2.49, \mathrm{MI}=0.27)$, and $(\mathrm{p} \leq 0.05, \mathrm{DC}=$ $-2.49, \mathrm{MI}=0.27$ ) respectively). Patients with vascular dementia had less pronounced agnosias compared with Alzheimer's disease ( $\mathrm{p} \leq 0.05$, DK = -2.39, $\mathrm{MI}=0.22)$ and visual hallucinations compared to mixed dementia $(\mathrm{p} \leq 0.05$, DK $=$ $-3.48, \mathrm{MI}=0.38$ ).

Thus, the analysis of clinical and psychopathological structure of higher mental functions and emotional sphere in patients with suicidal risk in various types of dementia allowed to determine the clinical diagnostic criteria of 
Table 1

Clinical diagnostic criteria for patients with high SR in different types of dementia

\begin{tabular}{|c|c|c|c|c|}
\hline \multirow{2}{*}{\multicolumn{2}{|c|}{ Indices }} & $\begin{array}{c}\text { Patients } \\
\text { with vascular dementia }\end{array}$ & $\begin{array}{c}\text { Patients } \\
\text { with Alzheimer's } \\
\text { Disease }\end{array}$ & $\begin{array}{l}\text { Patients with } \\
\text { mixed dementia }\end{array}$ \\
\hline & & \multicolumn{3}{|c|}{ Diagnostic coefficient (DC) } \\
\hline \multirow{3}{*}{ Thought disorder } & Circumstantial thinking & - & - & 2.30 \\
\hline & Delusions of self-effacement & 8.95 & 9.89 & - \\
\hline & Delusions of self-blame & - & 5.79 & - \\
\hline \multirow{7}{*}{$\begin{array}{l}\text { Emotional } \\
\text { sphere disorders }\end{array}$} & The feeling of hopelessness & 3.51 & 2.78 & 9.03 \\
\hline & The feeling of helplessness & - & - & 2.76 \\
\hline & Depressed mood & 2.00 & 4.82 & 2.79 \\
\hline & Asthenia & 4.18 & - & - \\
\hline & Inner agitation & - & 3.08 & - \\
\hline & Apathy & - & 2.85 & 3.01 \\
\hline & Exhaustion & - & - & 3.01 \\
\hline \multirow{4}{*}{$\begin{array}{l}\text { Volitional } \\
\text { disorders }\end{array}$} & Hypomimia & - & 2.72 & 6.02 \\
\hline & The reduction of volitional process & - & 1.60 & - \\
\hline & Decreased interest & - & 1.75 & - \\
\hline & Inhibition of autokinesia processes & - & 2.17 & - \\
\hline Speech disturbance & Bradylalia & 2.21 & 3.11 & 2.79 \\
\hline \multirow{2}{*}{$\begin{array}{l}\text { Attention } \\
\text { disturbance }\end{array}$} & Exhaustion & 1.17 & 1.96 & 1.46 \\
\hline & Poor attention & - & 3.60 & - \\
\hline
\end{tabular}

patients with high SR in different types of dementia (table 1).

4. Conclusions. Table 1 shows that the main clinical and psychopathological disorders in patients with high SR in various types of dementia are mental retardation, delusions of self-blame and self-effacement, predominance of hypomimia and oligothymia, decrease of tempo of speech, attention fatigue and numerous violations in the emotional sphere, which are mainly expressed by depressive affective manifestations. Patients in the control group had difficulty in planning and organizing activities, psychomotor agitation, the severity of fixative amnesia and difficulty concentration.

The obtained data should be taken into account when performing differential diagnostics of patients with SR in different types of dementia.

\section{Referenses}

1. World Health Organization. Suicide prevention (SUPRE). Geneva. Switzerland URL. 2007. Retrieved from: http://www.who.int/mental_health/prevention/suicide/suicideprevent/en/.

2. Yakhno, N.N., Zakharov, V.V., Lokshina, A.B. and others. (2011). Dementia: a guide for doctors. Moscow: Medpress-information. P. 272.

3. Mikhailova, N.M., Roshchina, I.F. (2013) Ethical aspects of dementia of late age: problems and solutions. Clinical and special psychology, 2, 36-42.

4. Zakharov, V.V., Voznesenskaya, T.G. (2013) Neuropsychiatric disorders: diagnostic tests. Moscow: MEDPress-Inform. P. 320.

5. Kozyolkin, O. A., Sikorska, M.V., Vizir, I.V., Neryanov, Yu.M. (2015) Dementia: teaching aids. Zaporozhye: [ZSMU]. P. 90.

6. Mudrenko, I.G. (2018) Clinical phenomenology of suicidal behavior in dementia of different types. Science Rise: Medical Science, 1(21), 38-44.

7. Mudrenko, I.G. (2017) Factors of suicidal behavior in patients with dementia. Medical psychology, 13 (47), 53-57.

8. Mudrenko, ${ }^{2}$.G. (2017) Pharmacological correction of depressive symptoms in patients with different clinical variants of dementia. Ukrainian Journal of Psychoneurology,25 (92), 49-54. 